\title{
UM OLHAR SOBRE A POÉTICA DOS PARANGOLÉS DE HÉLIO OITICICA
}

\section{Amanda Gatinho Teixeira PPGA-UFPA}

\section{Resumo}

O presente texto aborda a poética de Hélio Oiticica mediante os Parangolés, sua obra emblemática, em que o espectador tornando-se participador, podia vestir a cor, dançar, movimentar-se e ter a experiência da cor em seu próprio corpo. Assim como, analisar como se dá a fusão do criadorparticipador nos Parangolés, por meio do conceito de Anti-arte; apontar como se deu a apreensão e o uso de elementos do cotidiano; como emprestar uma gíria carioca, para dar nome a sua obra; e como utilizar os elementos construtivos estruturais populares da cultura do morro da Mangueira e do samba, vivência esta que teve conseqüências profundas no seu trabalho. Tanto que quase um ano e meio depois de seu primeiro contato, já estava levando os mangueirenses ao MAM-RJ, ato que contribuiu para o processo de dessacralização da obra de arte no Brasil.

\section{Palavras-chave:}

Parangolés, Hélio Oiticica, anti-arte.

\section{INTRODUÇÃO}

Artista de vanguarda, anarquista, polêmico e revolucionário. Esses podem ser alguns dos adjetivos para definir Hélio Oiticica, reconhecido internacionalmente como um dos nomes mais importantes da arte contemporânea. Seus trabalhos foram experimentais ao longo de toda sua vida, além de lutar contra a atitude meramente contemplativa por parte do expectador, ao propor relações sensoriais e corpóreas, gerando uma nova percepção de obra de arte, de acordo com as reflexões fenomenológicas de Merleau-Ponty.

Autor dos emblemáticos Parangolés, conceituado pelo próprio artista de "antiarte por excelência", que consistem basicamente em capas de tecidos

\section{Abstract}

The present text approaches the artistic poetics of Hélio Oiticica through the Parangolés, his emblematic work, in which the spectator becoming participant, could wear the color, dance, move and have the experience of color in his own body. As well as analyzing how the creator-participator merges in the Parangolés, through the concept of Anti-art; To point out how the apprehension and use of elements of daily life occurred; How to lend a carioca slang, to name his work; And how to use the popular structural constructive elements of the Mangueira hill and samba culture, an experience that had profound consequences for their work. So much so that almost a year and a half after his first contact, he was already taking the mangueirenses to MAM-RJ, an act that contributed to the process of desacralization of the work of art in Brazil. For this understanding, qualitative researches were carried out in bibliographies on the subject.

Keywords:

Hélio Oiticica. Parangolés. Anti-arte.

coloridos para vestir, dançar, "incorporar", ou ainda bandeiras, tendas, estandartes coloridos, que fundem elementos como: cor, poesia, fotografia, dança e música, e pressupõem uma manifestação cultural coletiva.

Arti-arte - compreensão e razão de ser do artista não mais como um criador para a contemplação mas como um motivador para a criação - a criação como tal se completa pela participação dinâmica do "espectador", agora considerado "participador". Anti-arte seria uma completação da necessidade coletiva de uma atividade criadora latente, que seria motivada de um determinado modo pelo artista: ficam portanto invalidadas as posições metafísicas, intelectualista e esteticista [...] é pois uma "realização criativa" o que propõe o artista, realização esta isenta de premissas morais, intelectuais ou estéticas - a anti-arte está 
isenta disto - é uma simples posição do homem nele mesmo e nas suas possibilidades criativas vitais. [...] "Parangolé" é a formulação definitiva do que seja a antiarte ambiental, justamente porque nessas obras foi-me dada oportunidade, a idéia, de fundir cor, estruturas, sentido poético, dança, palavra, fotografia - foi o compromisso definitivo com o que defino por totalidade-obra (OITICICA, 1966, p. 1-2). ${ }^{1}$

"Estou possuído", "Incorporo a revolta", "Capa da liberdade", "Da adversidade vivemos", estas são algumas das "mensagens" utilizadas sobre as capas. Nesta obra de Oiticica, o espectador é convidado a vesti-las e a dançar, determinando uma transformação expressivo-corporal. 0 ato de vestir os Parangolés traduz a totalidade vivencial da obra, pois ao desdobrá-la, tendo como núcleo central o seu próprio corpo, o espectador (agora considerado participador) vivência a transmutação espacial, percebendo-se como "núcleo" estrutural da obra.

\section{SIGNIFICADO DA PALAVRA PARANGOLÉ}

Oiticica descobriu essa palavra na rua, ao observar uma espécie de construção engendrada por um mendigo, no qual havia um pedaço de aniagem pregada, que dizia: "aqui é..." e a única coisa que ele entendeu que estava escrito, era a palavra "Parangolé".

Tal palavra é uma expressão idiomática, oriunda da gíria utilizada no Rio de Janeiro, que possui diferentes significados: "agitação súbita", "alegria", "animação", "situações inesperadas entre pessoas". Para o poeta Waly Salomão, autor de uma biografia de Oiticica, conta que na época a pergunta "qual é o parangolé? significaria o que é que há? como vão as coisas?" (REIS, 2006, p.34)

\section{ENTRE AS ESCOLAS DE SAMBA E A BRASILIDADE: O CONTEXTO HISTÓRICO- SOCIAL DE OITICICA.}

Os Parangolés surgiram na década de 60, período em que o Brasil vivia anos de censura e ditadura, mas também de uma crescente efervescência cultural, como o movimento musical conhecido por Tropicália². Esta foi uma das linhas de força entre as quais Oiticica se movimentava, assim como:

[...] a atração crescente que a música dos morros e as escolas de samba passaram a exercer sobre a classe média carioca; as modificações pelas quais as escolas de samba estavam passando, com a cada vez mais decisiva influência de carnavalescos de "classe média"; as ideias sobre cultura popular discutidas no âmbito do Centro Populares de Cultura (CPC) da Une, e do nascente Cinema Novo; as políticas oficiais para as favelas, e a alternativa urbanização/remoção; a descoberta contracultural das drogas e a criação de um novo mercado para o "tráfico de entorpecentes" dos morros cariocas (e também a criação de um novo tipo de "bandidagem"); os embates entre as várias definições de brasilidade e autenticidade em vários campos artísticos do país (incluindo a invenção da Mangueira como no espaço do samba mais autêntico). (VIANNA, 2001, p.3)

Esta vivência com a Mangueira marcou profundamente seu trabalho, tanto que os Parangolés são o primeiro fruto desse contato, gerando experiências ao mesmo tempo individuais e coletivas, mas que revelam a força de superação do individualismo.

\section{O EXPERIMENTALISMO [VIVENCIAL] NA MANGUEIRA}

Em 1964, Oiticica visitou pela primeira vez à favela levado pelo amigo escultor, Jackson Ribeiro que ajudava Amílcar de Castro na confecção de alegorias para o desfile da Escola de Samba Estação Primeira de Mangueira, do carnaval daquele ano. Hélio ficou tão fascinado com o que viu que passou a freqüentar o morro quase que diariamente, fazendo amizades, fumando e aprendendo a dançar samba, tanto que se tornou passista da Escola (Fig.1).

Oiticica começou a incorporar essa experiência com o espaço dionisíaco da Mangueira, o que teve conseqüências profundas, tanto na sua vivência quanto nos conceitos utilizados nos seus trabalhos artísticos. Para Hélio, o potencial encontrado no morro da Mangueira tratou-se da expressão de uma vitalidade criativa e transgressora, por ser capaz de superar estruturas de vida e de representação opressiva e estagnadas. Em carta para Lygia Clark, ele afirmava: "Quando me diziam - não vá a Mangueira. Pensava eu: eu não digo nada e vou, pois adorava" (OITICICA, apud BASUALDO, 2007, p. 17)

Porém, a relação de Oiticica com a favela da Mangueira, não pode ser considerada um fenômeno isolado e nem incomum no meio cultural e intelectual da época. Pois desde o final da década de 50, havia no Brasil um processo de aproximação entre a intelectualidade de esquerda e as camadas 


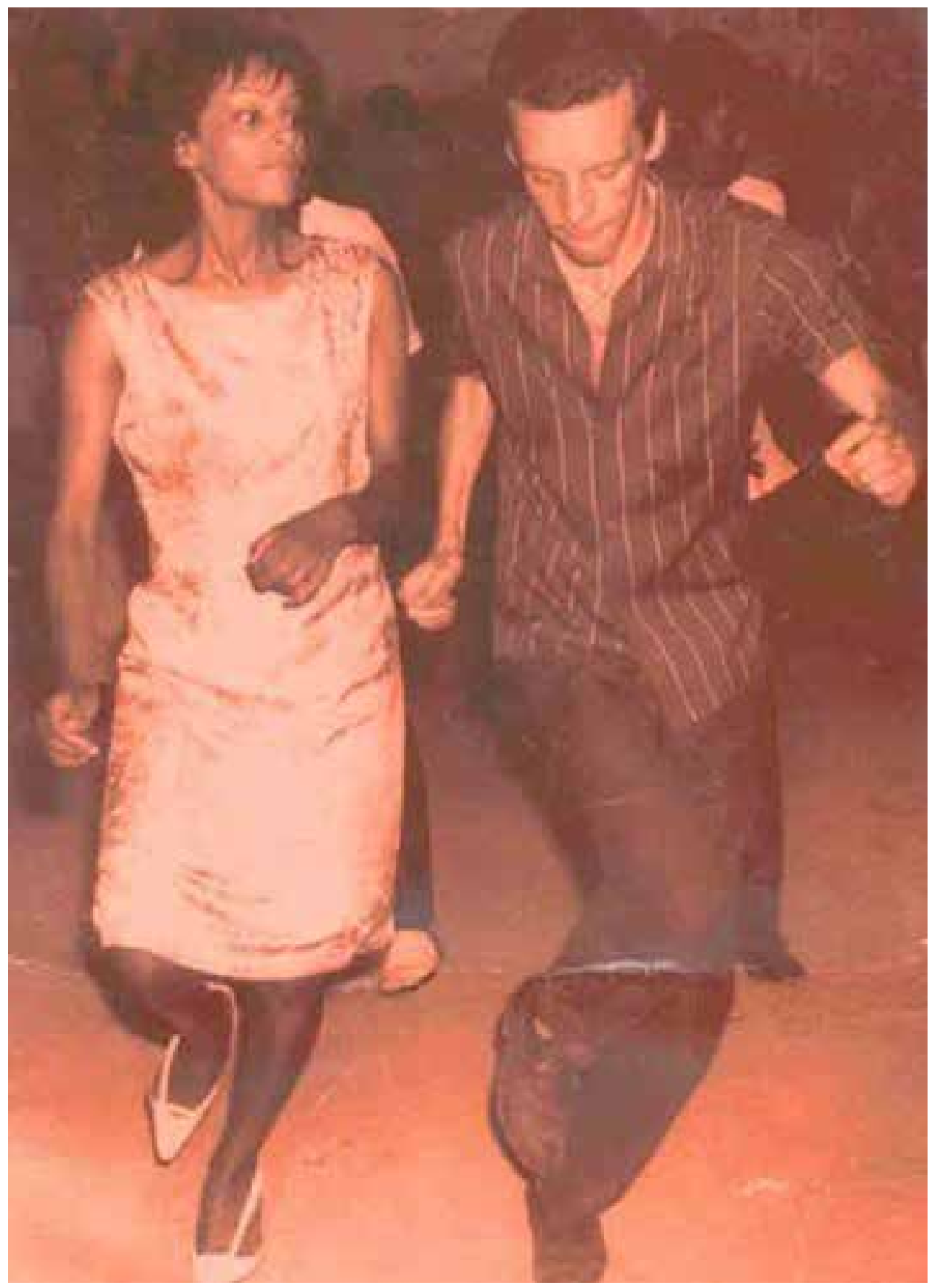

Figura 1 - Hélio Oiticica e Nininha Chochoba, ensaiando na Mangueira, 1965. Disponível em: <http://chacalog.zip.net/images/helionininha.jpg>

pobres da população, devido a contestação política sobre as desigualdades do país.

\section{ATO NO MAM-RJ E A DESSACRALIZAÇÃO DA OBRA DE ARTE}

$\mathrm{Na}$ inauguração da exposição "Opinião 65" no Museu de Arte Moderna do Rio de Janeiro, em agosto de 1965, Oiticica apresentou publicamente pela primeira vez seus Parangolés.

[...] essa mostra representou o momento privilegiado no qual as discussões sobre a volta da figuração tomaram corpo pela primeira vez e de forma variada [...] "Opinião 65" trouxe o posicionamento dos artistas após a instauração do regime militar. A exposição foi, no dizer de muitos críticos (como Frederico Morais, Wilson Coutinho, Mário Pedrosa e Ferreira Gullar), a primeira manifestação efetiva das artes plásticas com relação ao golpe de 1964 . (REIS, 2006, p. 31)

$\mathrm{Na}$ época em que se entrava nos museus com terno e gravata, Oiticica levou uma ala de passistas da favela e da escola de samba da Mangueira para apresentar, em seus corpos os Parangolés (Fig.2). 


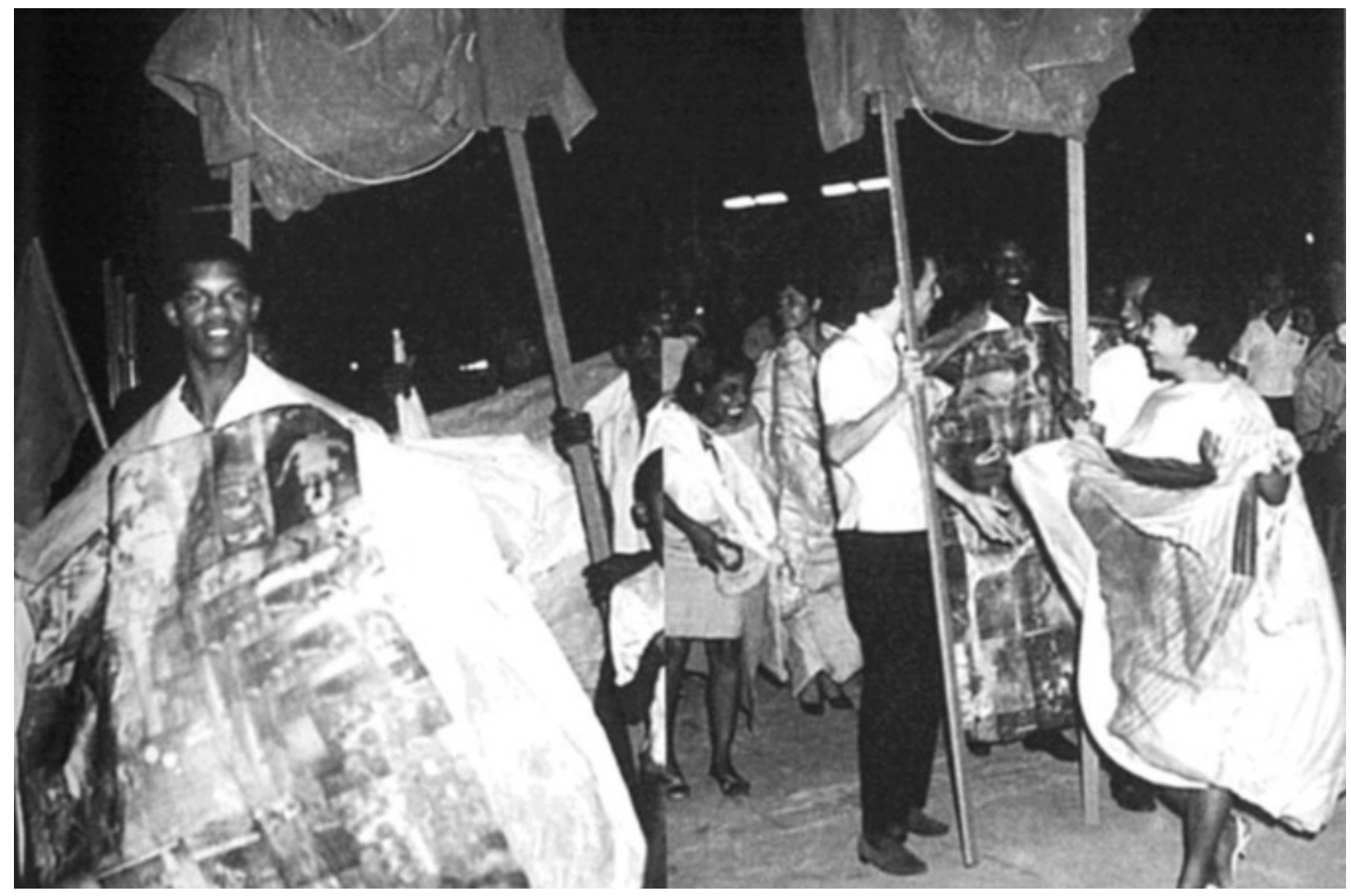

Figura 2 - Hélio Oiticica em manifestação no MAM-Rj. Fonte: SOUZA, [s/d], p.5.

Tal evento resultou em conflito, pois a direção do museu não permitiu a entrada e a exibição dos passistas dentro de suas instalações e a apresentação se deu nos jardins do MAM-RJ. 0 ato foi aplaudido pelos críticos, jornalistas, artistas e parte do público que lotavam as dependências. Os motivos alegados para o veto, apurados por jornais da época foram o barulho dos pandeiros, tamborins e frigideiras.

Este ato foi de grande importância, pois marcou o auge da dessacralização e a real tentativa de democratização da obra de arte, por meio da união da cultura popular com a erudita, firmando assim uma relativização cultural em que o samba conquista o sacrossanto espaço museal e este "desce" à quadra de samba.

\section{OITICICA E O PRINCÍPIO CRIATIVO DA ARQUITETURA FAVELAR}

O mundo das favelas cariocas dos anos 60 já era inteiramente urbano, porém, segregado do reconhecimento social da cidade. Habitado por uma população pobre, ora vistas como portadoras de riqueza folclórica de raízes, ora vistas como incivilizadas, atrasadas e perigosas. E é esse cenário que Hélio frequentava quase que diariamente, observando entre outros elementos, a arquitetura peculiar típica de paisagens urbanas periféricas.

Hélio buscaria nos Parangolés uma estrutura de caráter universal. Até certo ponto que o artista procura e elabora da favela e das manifestações populares (tanto as organizadas, como escolas de samba, frevos, feiras, ranchos, futebol, festas de toda ordem, quanto as espontâneas ou casuais) ou ainda as construções populares como as casas de mendigos; estas são suas estruturas universalizáveis e o que é retirado delas são os princípios de flexibilidade, participação, coletividade, improvisação e de ginga.

Seria, pois o "Parangolé" um buscar, antes de mais nada estrutural básico na constituição do mundo dos objetos, a procura das raízes da gênese objetiva da obra, a plasmação direta perceptiva da mesma. Esse interesse, pois, pela primitividade construtiva popular que soe acontecer nas 


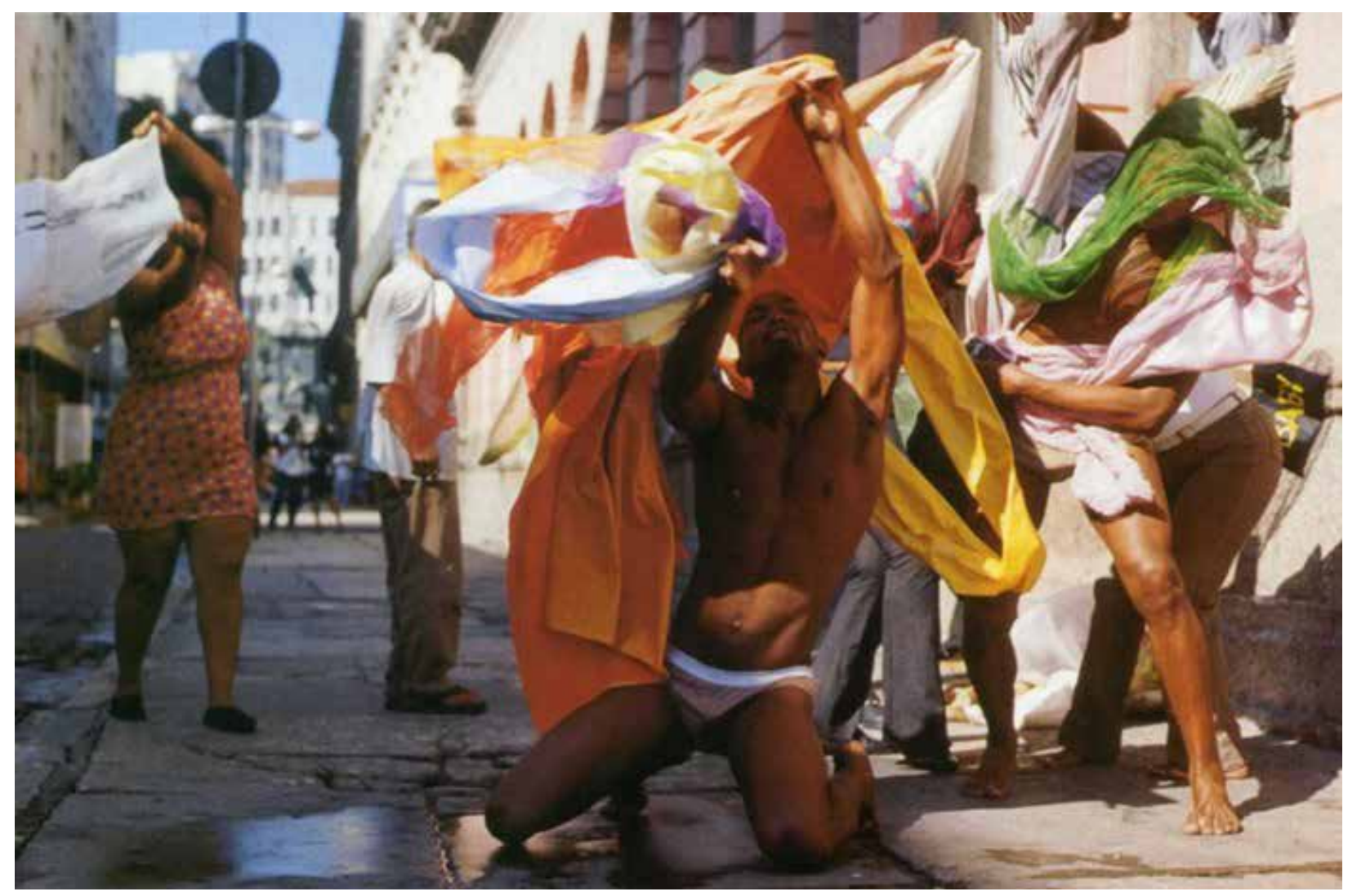

Figura 3 - Performance de populares com os Parangolés. Fonte: Parte integrante do catálogo da exposição "Além do espaço" de Hélio Oiticica.

paisagens urbanas, suburbanas, rurais, etc., obras que revelam um núcleo construtivo primário mas de um sentido espacial definido, uma totalidade (OITICICA, 1964a, p. 2)

A arquitetura orgânica da favela, assim como a dança, baseia-se também no improviso. A forma de um barraco é constantemente alterada, renovada e ampliada. É mais um abrigo que uma habitação, sua configuração é puramente contingencial, pois depende dos restos de materiais de construção disponibilizados, das condições do local, bem como as do construtor e sua família.

De acordo com Oiticica, na arquitetura da favela,

[...] está implícito um caráter do "Parangolé", tal a organicidade estrutural entre os elementos que $\mathrm{o}$ constituem e a circulação interna e o desmembramento externo dessas construções; não há passagens bruscas do "quarto" para a "sala" ou "cozinha", mas o essencial que define cada parte que se liga à outra em continuidade. (ibidem p.4)

Oiticica chegará à negação de posturas rígidas e elitistas, a partir da favela por meio da dança, no dia-a-dia e no espaço lá vivenciados.

\section{A DESCOBERTA DO ATO EXPRESSIVO CORPORAL E A INCORPORAÇÃO DO CORPO NA OBRA E DA OBRA NO CORPO}

O interesse de Oiticica pela dança, pelo ritmo, pelo samba, surgiu através de uma necessidade vital de desintelectualização e da necessidade de uma livre expressão, já que o próprio artista sentia-se ameaçado pela sua excessiva intelectualização.

\begin{abstract}
A dança é por excelência a busca do ato expressivo direto [...] a dança "dionisíaca" que nasce do ritmo interior do coletivo, que se externa como característica de grupos Populares, nações. etc. A improvisação reina aqui no lugar da coreografia organizada; em verdade quanto mais livre a improvisação melhor; há como que uma imersão no ritmo, uma identificação vital completa do gesto, do ato como ritmo, uma fluência onde o intelecto permanece como que obscurecido por uma força mítica interna, individual e coletiva (em verdade não se pode aí estabelecer a separação).
\end{abstract}

[...] A experiência da dança (o samba) deu-me portanto a exata idéia do que seja a criação pelo ato corporal, a contínua transformabilidade - De outro lado, porém, revelou-me o que chamo de 


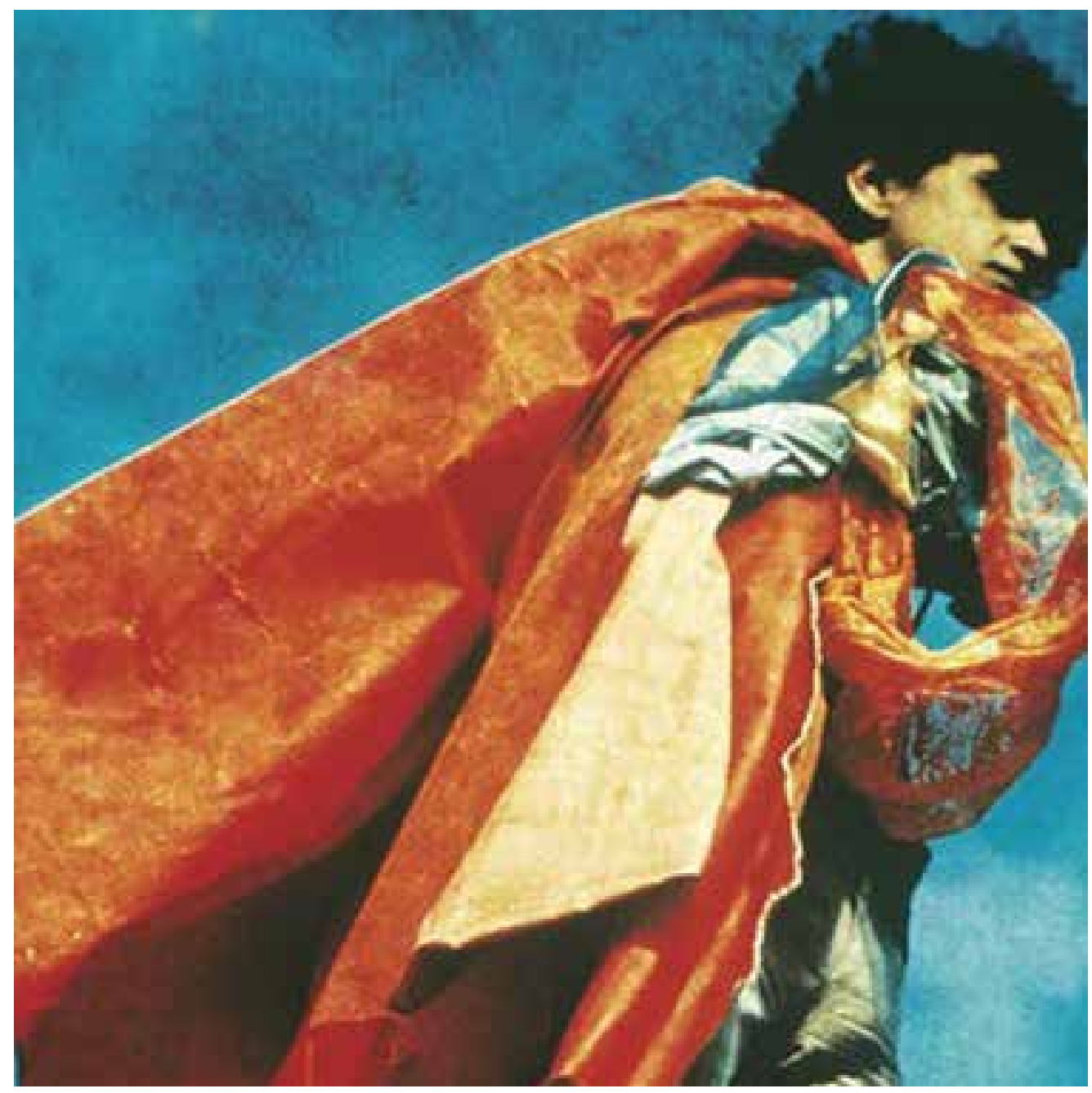

Figura 3 - Caetano Veloso usando P04 Parangolé 01, 1964. Disponível em: <http://3. bp.blogspot.com/_wyOQq3rG2wE/TEPE35mCixl/AAAAAAAAAYI/xw_TCcfBn6U/s1600/ parangole-1+helio.jpg>

"estar" das coisas, ou seja a expressão estática dos objetos, sua imanência expressiva, que é aqui o gosto da imanência do ato corporal expressivo, que se transforma sem cessar. (OITICICA, 1965, p. 1-4)

Os Parangolés necessitam da participação corporal direta, além de revestir o corpo, pede que este se movimente que dance (Fig.3). A dança é elevada a um nível de experimentalidade aberta. Por meio da expressão corporal, os Parangolés manifestam a cor no espaço ambiental através da aeração da cor.

[...] o espectador "veste" a capa, que se constitui de camadas de pano de cor que se revelam à medida em que este se movimenta correndo ou dançando. A obra requer aí a participação corporal direta; além de revestir o corpo, pede que este se movimente, que dance em última análise. O próprio "ato de vestir" a obra já implica numa transmutação expressivocorporal do espectador, característica primordial da dança, sua primeira condição. (OITICICA, 1964b, p. 1)
Para Hélio, a dança, representada pelo samba contribuiu para o ambiente de liberdade, alegria e ineditismo, uma perfeita comunhão da expressão catártica e extática.

[...] As imagens liberadas na dança são móveis, rápidas, inapreensíveis - são o oposto do ícone, estático e característico das artes ditas plásticas - em verdade a dança, o ritmo, são o próprio ato plástico na sua crudeza essencial - está aí apontada a direção da descoberta da imanência. Esse ato, a imersão no ritmo, é um puro ato criador, uma arte - é a criação do próprio ato, da continuidade; é também, como o são todos os atos da expressão criadora, um criador de imagens - aliás, para mim, foi como que uma nova descoberta da imagem, uma recriação da imagem, abarcando, como não poderia de ser, a expressão plástica na minha obra. (OITICICA apud FAVARETTO, 1992, p.115).

O Parangolé requer a participação mais ativa do espectador e não sua mera contemplação 


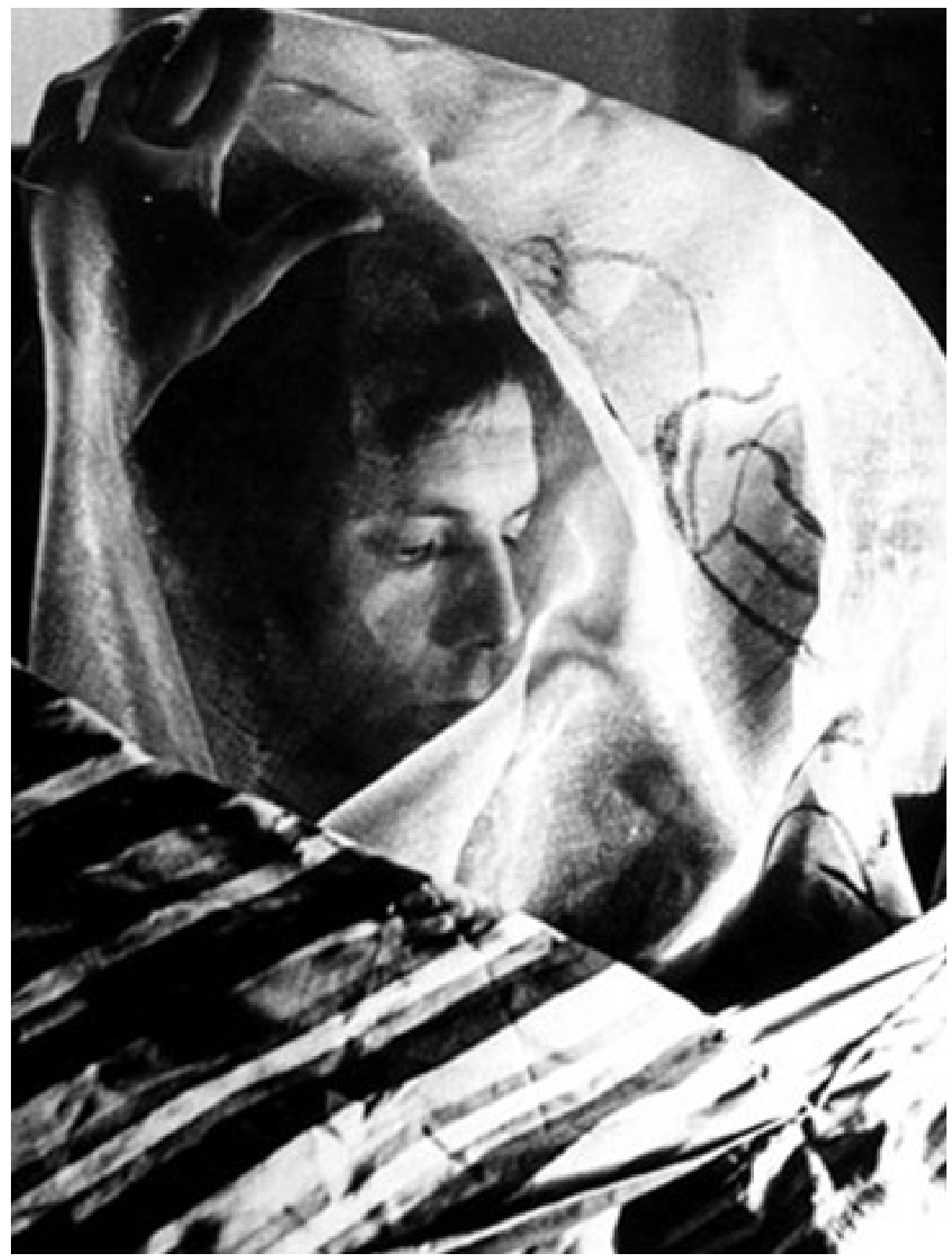

Figura 5 - Hélio Oiticica com o Parangolés P19, Capa 15. Disponível em: <http://jc3. uol.com.br/blogs/repositorio/parangole_oiticica_300_fi(1).jpg>

ou observação (Fig.4). O ato de vestir, andar ou dançar com um Parangolé traz um outro elemento presente a "estrutura-ação". A ação, ao modificar o caráter do espectador que se torna um participante, por meio da experimentação do elemento cor (estrutura-cor) no espaço, seja ela pela dança ou movimento. Assim, Oiticica assume um importante papel na especificidade da participação do espectador na arte brasileira. A participação ativa do espectador, vista como apreensão dos significados da obra, ligava-se para ele à participação corporal (vivencial) e à participação semântica (intelectiva).
Vestir as obras não é simplesmente fazer do corpo um suporte. De acordo com Oiticica, o Parangolé é a incorporação do corpo na obra e da obra no corpo.

Há aqui uma necessidade de "expressão-total", onde espectador e obra não mais se distanciem na praticidade do diálogo, mas que seja esse diálogo aqui procurado pela participação por "atos" desse espectador. O "espectador" passaria a ser então "participador" na obra. As formas fundamentais primeiras do Parangolé são a "tenda", o "estandarte" e a "capa", 3 posições espaciais na relação obraparticipador - $\mathrm{Na}$ "tenda" o participador penetra para desvendar a estrutura-cor espacial da obra; o "estandarte" é a estrutura ligada ao ato de carregar que aí se cumpre pelo participador; a "capa" que cumpre 3 ciclos: o participador assiste a outro que 
a veste, depois ele mesmo a veste e desvenda a estrutura-cor da mesma, e por fim participa de um vestir-assistir coletivo. A "capa" seria a valorização expressiva do inter-espaço do sujeito e da obraespaço inter-corporal.

Essa descoberta do espaço inter-corporal através do "ato de vestir" característico da "capa", isto é: houve aí a inserção do ritmo da dança como elemento intrínseco da "capa" e como integradora ambiental dessas formas do Parangolé. (OITICICA, s/d.)

Assim, nos Parangolés o corpo do espectadorparticipante passa a inserir-se na estrutura, tendo a experiência da cor em seu próprio corpo, atingindo um clímax corporal por meio da dança. A vivência da obra que se dava a nível subjetivo passa a ser "incorporada", uma vez que a relação entre obra e participante se torna orgânica (Fig.5).

\section{CONSIDERAÇÕES FINAIS}

Oiticica marcou seu nome na história da arte brasileira e mundial a partir de diversas contribuições. Equiparando-se a importância de alguns de seus antecessores ao buscar uma identidade nacional. Fato este que não era uma questão historicamente nova, haja vista que alguns pintores do romantismo do século XIX, tematizaram 0 indígena e nossa exuberância tropical de maneira idealizada aos moldes do academicismo europeu. Décadas mais tarde, em 1920, os modernistas paulistanos retomam essa busca, por meio da Antropofagia de Oswald de Andrade. Contudo, a presença desses elementos culturais da tropicalidade de Oiticica, não pode e nem deve ser considerado uma caricatura, de como somos compreendidos e nem tão pouco um elogio ufanista e sim um "estado típico da arte brasileira atual".

Através de sua posição anárquica desvenda a fragilidade de concepções elitistas da arte brasileira, ao mostrar um mecanismo ideológico e superficial; além de ser contra os padrões estéticos do mercado de arte, contra a crítica e com os museus e galerias. Seu trabalho foi marcado pela atuação com um compromisso vanguardista e com o exercício experimental da liberdade. Assim como, suas obras influenciaram decisivamente 0 entendimento da arte brasileira no século $X X$, ao redimensionar conceitos, reestruturar a dimensão dos "significados" das obras, reinventar a condição do espectador com a obra artística, em que a interatividade fosse motor vital para a apreensão dos sentidos. Obras como Bólides, Penetráveis, a ambientação Tropicália, explica esse sentido, assim como, os próprios Parangolés, por meio da organicidade da obra com o participante.

Neto de um importante anarquista, José Oiticica, Hélio descobriu na família a prática da filosofia libertária, o que certamente teve uma influência decisiva em todo o seu trabalho. Assim, o artista, sentiu a necessidade de dar um caráter de protesto em algumas de suas capas, surgindo o Parangolé Social e o Poético.

Com o Parangolé Poético, Oiticica achou essencial a participação de outros artistas, em que ficava reservado para vivências de ordem subjetiva. E a partir dessa concepção, surgiu o Parangolé Social ou de Protesto, em que o artista fazia uso da palavra, não apenas no sentido poético como polêmico discursivo, fazendo homenagens aos nossos mitos populares, aos nossos heróis e principalmente com uma "mensagem" social, política, protesto ou grito de revolta.

Mesmo que os Parangolés estejam intimamente ligados à arquitetura das favelas, do carnaval e a experiência do samba, estes não podem ser considerados mimese dos mesmos e Oiticica temia que fossem assim interpretados e nem tão pouco uma discussão sobre o suporte da obra de arte e sim promover uma ruptura do objeto artístico, questionando a sua fruição.

A complexidade de sua obra reflete a sua trajetória artística cercada de originalidade e genialidade o que fez Oiticica ganhar grande repercussão no cenário internacional, dando maior visibilidade para a produção artística brasileira.

\section{NOTAS}

1. Foi mantida a grafia original de Hélio Oiticica em todas as citações deste artigo.

2. Movimento cultural brasileiro que surgiu sob a influência das correntes artísticas de vanguarda e da cultura pop. Misturou manifestações tradicionais da cultura brasileira a inovações estéticas radicais. O nome do movimento foi dado por Hélio Oiticica, a partir de uma ambientação de 1967 , conhecida pelo mesmo nome. 


\section{REFERÊNCIAS}

BASUALDO, Carlos. (Org.) Tropicália: uma revolução na cultura brasileira (1967-1972). São Paulo: Cosac Naify, 2007.

FAVARETTO, Celso Fernando. A invenção de Hélio Oiticica. São Paulo: Edusp, 1992.

FILHO, Cesar Oiticica (Org.). Catálogo da exposição "Hélio Oiticica: museu é o mundo". Rio de Janeiro: Automática, 2011.

JACQUES, Paola Berenstein. Estética da ginga: a arquitetura das favelas através da obra de Hélio Oiticica. Rio de Janeiro: Casa da palavra/ RIOARTE, 2001.

OITICICA, Hélio. A dança da minha experiência. 1965. Disponível em: <http://www.itaucultural. org.br> :Itimo acesso realizado em 8 de Abril de 2011.

.Anotações sobre o "Parangolé". 1964b. Disponível em: <http://www.itaucultural.org.br> :Itimo acesso realizado em 8 de Abril de 2011.

Bases Fundamentais para uma definição do "Parangolé". 1964 a. Disponível em: <http:// www.itaucultural.org.br $>$ :Itimo acesso realizado em 8 de Abril de 2011.

Depoimento sobre o Parangolé. [S/d.] Disponível em: <http://www.itaucultural.org.br> :Itimo acesso realizado em 8 de Abril de 2011.

.Parangolé Poético e Parangolé Social.

1966 Disponível em: <http://www.itaucultural. org.br $>$ :Itimo acesso realizado em 8 de Abril de 2011.

Posição e programa. 1966. Disponível em: <http://www.itaucultural.org.br> :Itimo acesso realizado em 8 de Abril de 2011.

REIS, Paulo. Arte de vanguarda no Brasil: os anos 60. Rio de Janeiro: Jorge Zahar Ed., 2006.

SOUZA, Maria. Parangolé, política e poética do instante no "estado invenção" de Hélio Oiticica. [s/d]. Disponível em: <http://www.cleabrasil. com.br/Grupos/GRUPO\%205\%20\%20CINZA/ PARANGOL\%C3\%89\%20POL\%C3\%8DTICA\%20 E\%20PO\%C3\%89TICA\%20DO\%2OINSTANTE.pdf> Último acesso realizado em 18 de Maio de 2011.
VIANNA, Hermano. Hélio Oiticica como mediador cultural entre o asfalto e o morro. [ $s / d]$. Disponível em: < http://www.overmundo.com. $\mathrm{br} /$ banco/helio-oiticica-como-mediador-entreasfalto-e-morro> :Itimo acesso realizado em 18 de Maio de 2011.

\section{SOBRE A AUTORA}

Amanda Gatinho Teixeiraé mestra em Antropologia pela Universidade Federal do Pará (PPGA/ UFPA), na linha de pesquisa: Paisagem, Memória e Gênero. Membro do Grupo de pesquisa (Geca/ (NPQ) Grupo de Estudo Culturais na Amazônia. É pós-graduada em Design, Computação Gráfica e Multimídia pelo Instituto de Estudos Superiores da Amazônia (2013). Possui graduação em Artes Visuais com habilitação em Artes Plásticas pela Universidade Federal do Pará (2010). É técnica em Design Industrial pelo Centro Federal Tecnológico do Pará (2007). Possui experiência nas áreas de: Design Gráfico, História da Joalheria, História da Arte e do Design, Patrimônio Cultural, Restauração de Obras de Arte e esteve presente na equipe de restauro em telas da Catedral da Sé em Belém. De 2007 a 2011 realizou trabalhos de mediação cultural em espaços museológicos de Belém. 